\title{
Chronic Diarrhoea: A Rare Presentation Of Vitamin B12 Deficiency Anemia In Children
}

\section{Pun Narayan Shrestha, Bipin Khanal and Prakash Joshi}

Department of Paediatrics, Kanti Children Hospital, Maharajgunj, Kathmandu, Nepal

\section{Correspondence:}

Pun Narayan Shrestha

Department of Paediatrics,

Kanti Children Hospital,

Maharajgunj, Kathmandu, Nepal

Email: shrestha-pn@hotmail.com

DOI: $10.3126 /$ jnps.v41i2.34916

Submitted on: $2021 / 3 / 23$

Accepted on: 2021/7/4

Acknowledgements: We would like to acknowledge Dr Sumit Agrawal, Dr Saroj Shah Dr Avinandan Srivastava and nursing staff from PICU who were also involved in care of the patient. Father of the patient deserves our vote of thanks for giving written consent to publish this case report.

Funding: Nil

Conflict of Interest: None declared

Permission from IRB: Yes
To cite this article: Shrestha PN, Khanal B, Joshi P. Chronic Diarrhoea: A Rare Presentation Of Vitamin B12 Deficiency Anemia In Children. J Nepal Paediatr Soc. 2021;41(2):278-81.

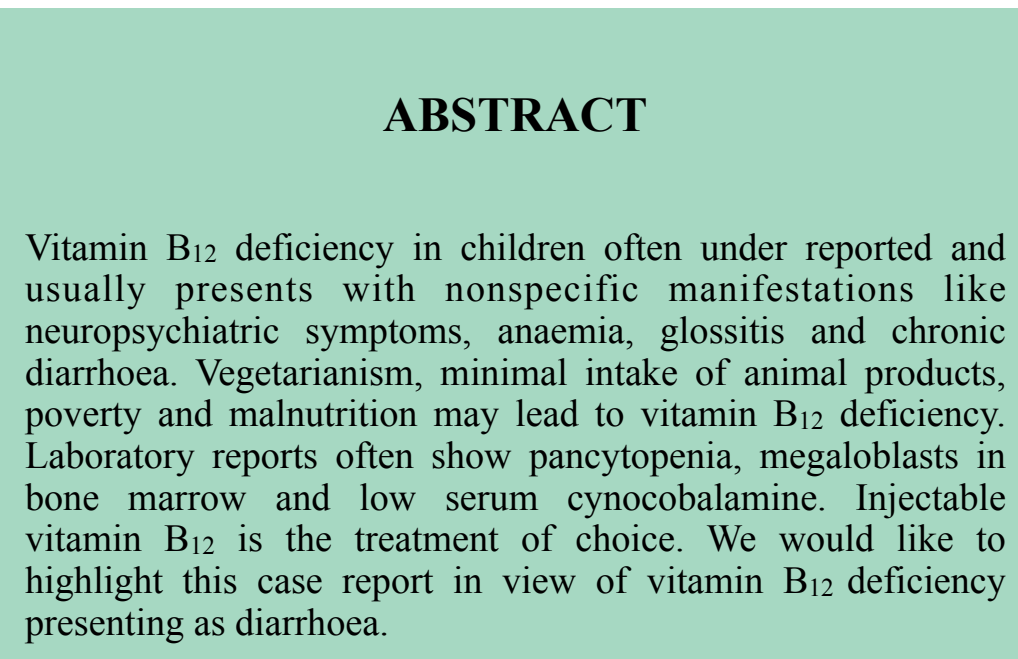

Key words: diarrhoea; pancytopenia; vitamin $\mathrm{B}_{12}$ 


\section{INTRODUCTION}

Chronic diarrhoea is a common problem among children. Most authors agree with 14 days of symptoms as criteria for chronic diarrhoea while others use a cutoff of four weeks. ${ }^{1}$ Vitamin $\mathrm{B}_{12}$ is essential for DNA and RNA synthesis, hematopoiesis, cognitive function as well as cell growth and proliferation particularly for rapidly growing cells such as gastrointestinal cells and bone marrow, also important for the myelination and maintenance of nervous system. ${ }^{2}$

Though vitamin $\mathrm{B}_{12}$ deficiency affects most of the systems, macrocytic anaemia is the classic presentation of Vitamin $\mathrm{B}_{12}$ deficiency. ${ }^{3}$ Other symptoms include neuropsychiatric problems such as numbness and limb paresthesias, loss of position and vibratory sensation, difficulty walking, depression, irritability, diminished cognitive function, memory impairment and psychosis. They are also at increased risk of cardiovascular disease, stroke, coronary artery disease and peripheral artery disease. $^{4}$ Though glossitis, cheliosis, anorexia, constipation and weight loss are well known symptoms, chronic diarrhoea is one of the rare presentations of vitamin $B_{12}$ deficiency. ${ }^{5}$ Considering the rapid turnover of enterocytes, it is conceivable that diarrhoea may be the manifestation of an 'enterocytopathy' due to vitamin $\mathrm{B}_{12}$ deficiency. ${ }^{5}$ Improving early feeding practices with foods rich in vitamin $B_{12}$ such as animal source foods and fortified foods may help to reduce the deficiency. ${ }^{2}$

\section{CASE REPORT}

A previously healthy, 13 year old girl from Kalikot, Nepal was presented in Kanti Children Hospital, Maharajgunj, Kathmandu, Nepal on January 2021 with complaints of loose stool seven to 10 episodes per day for one year and vomiting on and off for one and half month. The stool was semi - solid to watery in consistency, not mixed with blood and mucus. Vomiting was non projectile in nature, two to three episodes per day containing ingested food particles, non-bilious and not stained with blood. She had history of generalised weakness. She had no history of abdominal pain or distension, yellowish discolouration of body or eyes, fever, burning micturition, skin rashes, joint pain or bony pain, altered sensorium, abnormal body movements, cough, shortness of breath and swelling of body. No history of contact with tuberculosis and proven COVID-19 case. She was from lower socioeconomic status. Though she was non - vegetarian, she rarely used to take animal food products in her diet.

On admission, she was fully conscious, cooperative and thin built with weight $26 \mathrm{Kg}$. Her respiratory rate was 22 per minute, heart rate 98 beats per minute, blood pressure $90 / 60 \mathrm{~mm} \mathrm{Hg}$, temperature $37.2^{\circ} \mathrm{C}$ and oxygen saturation of $98 \%$ at room air. On general physical examination, she was pale but no jaundice, lymphadenopathy, edema and signs of dehydration. On abdominal examination, mild tenderness was present in periumbilical region with no evidence of any lumps or organomegaly. Other systemic examinations were normal findings.

On complete blood count (CBC), she was pancytopenic with Hemoglobin $(\mathrm{Hb})=4 \mathrm{~g} / \mathrm{dl}$, total leucocyte count $($ TLC $)=2.6 \times 10^{9} / 1$ (Neutrophils $=60 \%$, lymphocytes $=30 \%$, monocyte $=6 \%$ and eosinophils $=4 \%$ ), platelet count $=107 \times 10^{9} / 1$, erythrocyte sedimentation rate $(E S R)=50 \mathrm{~mm} / \mathrm{hr}$, mean corpuscular volume $(\mathrm{MCV})=115 \mathrm{fl}$, mean corpuscular haemoglobin concentration $(\mathrm{MCHC})=$ $300 \mathrm{~g} / \mathrm{l}$, red cell distribution width $(\mathrm{RDW})=14$. Peripheral blood smear examination revealed presence of normocytic normochromic with few macrocytes and ovalocytes, reduced WBC and platelet count and absence of atypical cells. Random blood sugar, renal function test, liver function test, iron profile, urine and stool routine and microscopic examination were normal. Stool for occult blood was negative. Serum folic acid level was $6.54 \mathrm{ng} / \mathrm{ml}$ (normal range: $5.21-20 \mathrm{ng} /$ $\mathrm{ml})$ and serum cyanocobalamine (vitamin $\mathrm{B}_{12}$ ) level was $12.5 \mathrm{pg} / \mathrm{ml}$ (normal range: $200-1100 \mathrm{pg} / \mathrm{ml}$ ).

Her Anti-Nuclear Antibody (ANA), SARS-CoV 2 PCR and HIV ELISA tests were all negative. Bone marrow aspiration showed normoblastic maturation of RBC with few megaloblasts, normal maturation of WBC and negative for malignancy. Abdominal ultra-sonograph and barium meal follow through were normal. 
With all these history, clinical examination findings and laboratory investigation reports, she was diagnosed as a case of chronic diarrhoea with vitamin $\mathrm{B}_{12}$ deficiency megaloblastic anaemia. She was treated with injection cyanocobalamine (1000 mcg intramuscular daily for three days, then on weekly basis). She was also treated with tab folic acid, zinc, vitamin $\mathrm{E}$, albendazole, vitamin $\mathrm{A}$ and ceftriaxone as supportive therapy. Her clinical symptoms improved gradually. Repeat investigation was done after $16^{\text {th }}$ day of admission which revealed haemoglobin $8.5 \mathrm{gm} / \mathrm{dl}$ with normal WBC and platelets count. Repeat vitamin $\mathrm{B}_{12}$ level was $1702 \mathrm{pg} / \mathrm{ml}$. She was discharged on injection cyanocobalamine weekly for three more weeks and advised for follow up then after.

\section{DISCUSSION}

Vitamin $\mathrm{B}_{12}$ deficiency in children is a significant preventable public health problem. It is often under reported in children from developing countries, with a varying prevalence of $21-45 \%$. Vegetarianism, minimal intake of animal products, poverty and malnutrition can lead to vitamin $B_{12}$ deficiency. ${ }^{6}$ A recent population-based study in the Bhaktapur municipality of Nepal identified $17 \%$ vitamin $\mathrm{B}_{12}$ deficiency among breastfed to one year old infants. ${ }^{7}$ In another study, among six to 35 months old Nepalese children presenting with diarrhoea, $41 \%$ were found to have vitamin $B_{12}$ deficiency. ${ }^{8}$ Few cases were reported in adult as vitamin $\mathrm{B}_{12}$ deficiency associated with chronic diarrhoea. Gastrointestinal symptoms particularly chronic diarrhea is less common manifestation of vitamin $\mathrm{B}_{12}$ deficiency. There are very few studies done regarding association of chronic diarrhea and vitamin $B_{12}$ deficiency megaloblastic anemia in paediatric population.

Vitamin $\mathrm{B}_{12}$ is not produced by humans and it must be consumed with diet. After binding with intrinsic factor, it is absorbed in the distal ileum. Similarly a case report done by Kumar $\mathrm{KJ}$ et al reported that vitamin $\mathrm{B}_{12}$ deficiency associated with persistent diarrhoea, thrombocytopenia and anaemia. ${ }^{3}$ Andrès et al reported out of 201 Vitamin $\mathrm{B}_{12}$ deficiency patients, pancytopenia in $5 \%$, pseudo-thrombotic microangiopathy in $2.5 \%$, and hemolytic anaemia in $1.5 \% .{ }^{9}$ Other symptoms include anorexia, sparse hair, failure to thrive, abnormal pigmentation, hypotonia, and organomegaly. ${ }^{10}$ However in our case these symptoms were absent.

\section{CONCLUSIONS}

Chronic diarrhoea may be a manifestation of vitamin $B_{12}$ deficiency. The presence of anaemia in cases of chronic diarrhoea should raise the suspicion of megaloblastic anaemia secondary to vitamin $\mathrm{B}_{12}$ deficiency when other causes of chronic diarrhoea are ruled out.

\section{REFERENCES}

1. Zella GC, Israel EJ. Chronic Diarrhea in Children. Pediatr Rev. 2012;33(5):207-218. DOI: 10.1542/pir.33-5-207.

2. Ng'eno B, Perrine C, Whitehead R, Subedi GR, Mebrahtu S, Dahal P, et al. High Prevalence of Vitamin B12 Deficiency and No Folate Deficiency in Young Children in Nepal. Nutrients. 2017 Jan;9(1):72-5. DOI: 10.3390/ nu9010072

3. Kumar KJ, Prudhvi S, Balaji K, Rahul R. Persistent diarrhea, hemolytic anemia, and splenohepatomegaly due to Vitamin B12 deficiency in an infant. J of Appl Hematol. 2018;9(4):148-50. DOI: 10.4103/joah.joah_36_18

4. Reenan J. Clinical Manifestations of Vitamin B-12 Deficiency. AMA J Ethics. 2006;8(6):392-6. DOI: 10.1001/ virtualmentor.2006.8.6.cprl1-0606.

5. Mirijello A, Vallone C, De Cosmo S, Landolfi R, Addolorato G. Chronic diarrhea in a patient with severe vitamin B12 deficiency: a rare clinical manifestation. Scand J Gastroenterol. 2016;51(6):763-4. DOI: 10.3109/00365521.2015.1136353 
6. Umasanker S, Bhakat R, Mehta S, Rathaur VK, Verma PK, Bhat N K, et al. Vitamin B12 deficiency in children from Northern India: Time to reconsider nutritional handicaps. J Family Med Prim Care. 2020;9(9):4985-91. DOI: 10.4103/jfmpc.jfmpc_712_20

7. Ulak M, Chandyo RK, Thorne-Lyman AL, Henjum S, Ueland PM, Midttun $\varnothing$, et al. Vitamin status among breastfed infants in Bhaktapur, Nepal. Nutrients. 2016 Mar;8(3):149. DOI: 10.3390/nu8030149.

8. Ulak M, Chandyo R, Adhikari RK, Sharma PR, Sommerfelt H, Refsum H, et al. Cobalamin and folate status in 6 to 35 months old children presenting with acute diarrhea in Bhaktapur, Nepal. PLoS ONE. 2014;9(3):e90079. DOI: 10.1371/journal.pone.0090079.

9. Andrès E, Affenberger S, Zimmer J, Vinzio S, Grosu D, Pistol G, et al. Current hematological findings in cobalamin deficiency. A study of 201 consecutive patients with documented cobalamin deficiency. Clin Lab Haematol 2006;28:50-6. DOI: 10.1111/j.1365-2257.2006.00755.x

10. Black MM. Effects of Vitamin B12 and folate deficiency on brain development in children. Food Nutr Bull 2008;29:126-31. DOI: 10.1177/15648265080292S117 